Prethodno priopćenje

"UDK: 657:005](497.6)

004.451:368](497.6)"

Datum primitka članka u uredništvo: 21. 9. 2020.

Datum slanja članka na recenziju: 8. 10. 2020.

Datum prihvaćanja članka za objavu: 30. 11. 2020.

Dr. sc. Ana-Marija Stjepić ${ }^{1}$

\title{
ISTRAŽIVANJE PRIHVATA SUSTAVA POSLOVNE INTELIGENCIJE U HRVATSKIM MALIM I SREDNJIM PODUZEĆIMA TERCIJARNOGA SEKTORA KROZ DIMENZIJE TOE OKVIRA: PRIMJENA FAKTORSKE ANALIZE
}

\author{
EXAMINATION OF BUSINESS INTELLIGENCE SYSTEM \\ ADOPTION IN CROATIAN TERTIARY SMALL AND MEDIUM \\ ENTERPRISES THROUGH THE TOE FRAMEWORK \\ DIMENSIONS: APPLICATION OF FACTOR ANALYSIS
}

SAŽETAK: Mala i srednja poduzeća predstavljaju gospodarsku okosnicu većine Europskih zemalja pa tako i Republike Hrvatske čiji je poslovni uspjeh sve više usmjeren na pravovremenu implementaciju i primjenu adekvatnih tehnoloških inovacija. Jedna od najprepoznatijih tehnoloških inovacija koja pomaže poduzećima pri donošenju kvalitetnijih poslovnih odluka je sustav poslovne inteligencije. U cilju identifikacije potencijalnih odrednica uspješnog prihvata sustava poslovne inteligencije unutar dimenzija odabranog teorijskog okvira Tehnologija - Organizacija - Okruženje na uzorku hrvatskih malih i srednjih poduzeća tercijarnoga sektora, provedena je metoda faktorske analize. Podaci su prikupljeni uz pomoć provedenog anketnog upitnika na uzorku od 100 hrvatskih malih i srednjih poduzeća tercijarnoga sektora. Provedena faktorska analiza rezultirala je s četiri izlučena faktora unutar tehnološke dimenzije, tri faktora unutar organizacijske i dva faktora unutar dimenzije okruženja koji odgovaraju prvotno postavljenim odrednicama dimenzija izabranog teorijskog okvira.

KLJUČNE RIJEČI: sustav poslovne inteligencije, prihvat, tercijarni sektor, Republika Hrvatska, faktorska analiza, Tehnologija - Organizacija - Okruženje

\begin{abstract}
Small and medium-sized enterprises represent the economic backbone of most European countries, including the Republic of Croatia. Today, most enterprises focus their business success on timely and adequate technological innovations adoption. One of the most recognized modern technological innovations that provide enterprises with
\end{abstract}

${ }^{1}$ Dr. sc. Ana-Marija Stjepić, Ekonomski fakultet - Zagreb, Trg J. F. Kennedyja 6, 10000, Zagreb 
more efficient business decision-making processes is the business intelligence system. For this purpose, this paper aims to determine potential determinants of successful business intelligence system adoption within the dimensions of the chosen theoretical framework Technology - Organization - Environment. Research data were collected via a survey questionnaire on a sample of 100 tertiary Croatian small and medium-sized enterprises and then analyzed using the factor analysis method. The conducted factor analysis resulted in four factors within the technological dimension, three factors within the organizational dimension, and two factors within the environmental dimension. The obtained results match the initially set dimensional determinants of the chosen theoretical framework.

KEYWORDS: business intelligence systems, adoption, tertiary sector, Republic of Croatia, factor analysis, Technology - Organization - Environment framework

\section{UVOD}

Današnja globalizacija pridonosi sve snažnijem ljudskom napretku i razvoju na individualnoj i poslovnoj razini kao i sve snažnijoj sinergiji i zajedničkom djelovanju, upravo zbog sve većeg uzleta internetske i informacijsko-komunikacijske tehnologije. Shodno tome, primjećuje se povećani interes znanstvenih pa tako i praktičnih krugova, za sigurnom, jednostavnom te uspješnom implementacijom i primjenom odnosno adekvatnim prihvatom, novih inovativnih tehnoloških rješenja. Upravo su nova tehnološka rješenja ključan element koji oblikuje daljnja poduzeća (Bellini, 2012) i koja im pomažu u efikasnom obavljanju poslovanja pri sve složenijim i zahtjevnijim tržišnim uvjetima. Moderno, turbulentno okarakterizirano poslovanje, uzrokuje ovisnost poduzeća svih veličina o informacijama koje prikuplja iz svojih internih i vanjskih izvora. Razlog počiva u vrijednosti informacije koja dobivena u pravo vrijeme, usmjerena pravoj osobi i iskorištena u pravu svrhu može osigurati današnjem poduzeću konkurentsku prednost i učinkovit nastavak poslovanja. Upravo ovdje nastupaju tehnologije poput sustava poslovne inteligencije.

Sustav poslovne inteligencije zastupa tehnološku perspektivu koncepta poslovne inteligencije (Sang, Xu i de Vrieze, 2016; Gonzales i Wareham 2019 prema Acheampong i Moyaid, 2016) koji po svojoj definiciji označava strategiju, metode, tehnike i alate za podršku strateškom poslovanju poduzeća (Apraksin, Stylianou i Scherbinin, 2018). Primjena sustava poslovne inteligencije u poduzeću podrazumijeva uporabu različitih tehnologija, alata i aplikacija kojima se izvršava pohrana podataka, njihova analiza te distribucija novoga znanja (Elbashir, Collier i Davern, 2008). U svrhu pravilna funkcioniranja sustava poslovne inteligencije unutar poslovanja poduzeća, potrebno je osigurati i njegovu adekvatnu implementaciju te primjenu u poduzeću. Obzirom da svako poduzeće ima svoje interne i eksterne karakteristike s kojima i u kojima djeluje, potrebno je u skladu s njima prihvaćati nove tehnološke inovacije. Shodno tome, tijekom vremena razvijeno je nekoliko različitih teorija, okvira i modela za potrebe ispitivanja prihvata novih tehnoloških rješenja u poduzećima no za potrebe ovoga rada izabran je teorijski okvir pod imenom Tehnologija - Organizacija - Okruženje.

U temama prihvata novih tehnoloških inovacija u poduzećima, mala i srednja poduzeća su nerijetko i nepravedno znala biti zanemarena premda je njihova gospodarska važnost 
ključna za mnoge Europske zemlje pa tako i Republiku Hrvatsku. Prema Ceporu (2019) sektor malih i srednjih poduzeća predstavljao je oko $99 \%$ u ukupnom broju svih poduzeća Republike Hrvatske te je generirao oko $45 \%$ aktivnih radnih mjesta uz ostvarivanje izvoznih aktivnosti u udjelu od $46 \%$. Također, mala i srednja poduzeća najvećim udjelom posluju u sektoru uslužnih djelatnosti odnosno tercijarnom sektoru čije poslovanje se ponajviše temelji na pravodobnim i točnim informacijama čime se posebice ističe njegova potreba za usvajanjem tehnologija kao što su sustavi poslovne inteligencije (Hrvatski zavod za zapošljavanje, 2012; Radoš i sur., 2014). Upravo radi toga, u području djelatnosti tercijarnoga sektora, primjena sustava poslovne inteligencije zauzima sve veću pozornost zbog doprinosa kojeg ostvaruje u boljoj i preciznijoj organizaciji, manipulaciji te ekstrakciji vrijednih informacija iz velike količine podataka, a koji pristižu iz niza internih i eksternih izvora u okviru izvršavanja poslovanja. Tako primjerice, u financijskom i bankarskom sektoru sustavi poslovne inteligencije pridonose praćenju i kontroli stanja računa svake poslovnice odnosno odnosa troškova i profita svake pojedine poslovnice banke, povećanju produktivnosti poslovnica, lakšoj komunikaciji i distribuciji informacija između različitih sektora i poslovnica itd. (Biroğul i Gültekin, 2020). S druge strane, u području obrazovanja, sustavi poslovne inteligencije omogućuju praćenje i analizu interne kvalitete rada visokoobrazovnih institucija te potpomažu u procjeni eksternih akreditacijskih aktivnosti (Cvitanušić Brečić, 2020). Osim u navedenim djelatnostima, različitim tehnikama, metodama i alatima, sustavi poslovne inteligencije ostvaruju svoje koristi i u djelatnostima s područja medicine (Arefin, Hoque i Rasul, 2020), pogotovo sada u vrijeme COVID-19 pandemije pri čemu su neke bolnice odlučile koristiti sustav poslovne inteligencije za detekciju novih slučajeva zaraze i donošenja pravovremenih odgovora na njezino daljnje širenje (Sechi i sur., 2020). Područja marketinga, ugostiteljskih i smještajnih objekata također su neka od djelatnosti tercijarnoga sektora koja ostvaruju koristi od primjene sustava poslovne inteligencije pri obavljanju svojih poslovnih aktivnosti (Becerra-Godinez i sur., 2020).

Obzirom na sve navedene važnosti prihvata sustava poslovne inteligencije u malim i srednjim poduzećima tercijarnoga sektora, a koje još nisu istražene na području Republike Hrvatske, ovaj rad ima cilj identificirati odrednice triju dimenzija teorijskog okvira Tehnologija - Organizacija - Okruženje, a koje bi ostvarivale potencijalni utjecaj na prihvat sustava poslovne inteligencije u malim i srednjim poduzećima tercijarnoga sektora u Republici Hrvatskoj. Odabrani teorijski okvir Tehnologije - Organizacije - Okruženja promatra prihvat tehnološkog rješenja iz unutarnje i vanjske perspektive poslovanja poduzeća, čime se obuhvaćaju svi potencijalni pokretači i rizici u prihvatu tehnologije kao što je sustav poslovne inteligencije. Obzirom na tehnološku prirodu funkcioniranja sustava poslovne inteligencije koje ovisi o infrastrukturnoj dostupnosti, podatkovnoj kvaliteti te čije djelovanje ulazi u domenu različitih poslovnih procesa (od skladištenja, preko prodaje do procesa odlučivanja), potrebno je ispitati tehnološke i organizacijske temelje poduzeća koje planira prihvatiti sustav poslovne inteligencije. S druge strane, sustav poslovne inteligencije postaje sve popularnija tehnologija za uspostavu konkurentske prednosti na tržištu (Eidizadeh, Salehzadeh i Esfahani, 2017; Jalil i sur., 2019) te kao takva zahtijeva i kvalitetnu postimplementacijsku podršku od strane stručnog informatičkog kadra. Stoga je za prihvat sustava poslovne inteligencije bitno razmotriti i vanjske utjecaje tržišta na kojem poduzeće posluje, a koje upravo TOE okvir razmatra pri istraživanju prihvata tehnoloških inovacija. 
Empirijsko istraživanje provedeno u ovome radu obuhvatilo je izabrane odrednice unutar okvira Tehnologija - Organizacija - Okruženje za svaku od tri definiranih dimenzija okvira: tehnološku, organizacijsku i dimenziju okruženja. U svrhu otkrivanja i testiranja strukture postavljenih dimenzija okvira Tehnologija - Organizacija - Okruženje za ispitivanje odrednica utjecaja na prihvat sustava poslovne inteligencije na malim i srednjim poduzećima tercijarnoga sektora, provedena je metoda faktorske analize (Hair i sur., 2005).

Struktura rada sastoji se od pet cjelina. U uvodnom dijelu rada, navodi se uloga i važnost prihvata sustava poslovne inteligencije u malim i srednjim poduzećima tercijarnoga sektora Republike Hrvatske. U drugom dijelu rada ističu se izabrane odrednice teorijskog okvira Tehnologija - Organizacija - Okruženje, a koje će se ispitivati unutar svake od njegovih triju postavljenih dimenzija. Empirijsko istraživanje prikazano je u trećem dijelu rada. Prikaz i interpretacija dobivenih rezultata istraživanja predstavljena je u četvrtom dijelu rada. U petom dijelu rada iznesena su zaključna razmatranja, istaknuta su ograničenja te dane preporuke za daljnja istraživanja u ovome području.

\section{ODREDNICE PRIHVATA SUSTAVA POSLOVNE INTELIGENCIJE UNUTAR TOE OKVIRA}

Prihvat tehnoloških inovacija u poslovanjima poduzeća postaje sve aktualnija tema znanstvenih i praktičnih krugova diljem svijeta upravo radi njihove prepoznate važnosti kao ključnih pokretača mnogih gospodarstava (Moore i Benbasat, 1991; Troshani, Rampersad i Plewa, 2011). Isto tako i prihvat sustava poslovne inteligencije kao jedne od današnjih ključnih tehnologija za održavanje uspješnosti suvremenog poslovanja, kroz vrijeme postaje sve istaknutija tema autora mnogih znanstvenih radova (npr. Azvine i sur., 2006; Porfirio i dos Santos, 2011; Arnott, Lizama i Song, 2017; Ahmad i Miskon, 2019).

Povijest teorijskih okvira i modela koji istražuju prihvat različitih tehnoloških inovacija seže još u 60-e godine prošloga stoljeća kada je od strane autora Fishbeina 1967. godine razvijena jedna od najpoznatijih teorija za istraživanje prihvata tehnoloških inovacija pod imenom „Teorija razložne akcije“. Na spomenutoj teoriji gradile su se daljnje teorije i okviri za prihvat tehnoloških inovacija u poduzećima poput: modela prihvaćanja tehnologije (Davis, 1985), teorija planiranog ponašanja (Ajzen, 1985), teorija difuzije inovacije (Rogers, 1983), model opće teorije i upotrebe tehnologije (Venkatesh i sur., 2003) i dr. Osim spomenutih okvira, teorija i modela koji se primjenjuju u istraživanjima prihvata različitih tehnoloških inovacija u poduzećima, posebnu pozornost zauzima teorijski okvir pod imenom Tehnologija - Organizacija - Okruženje. Ovaj teorijski okvir razvijen je 1990. godine od strane autora Tornatzky i Fleischer te objašnjava utjecaj tehnološke, organizacijske i dimenzije okruženja na prihvat tehnoloških inovacija u poduzeću (Baker, 2012). Pri tome, tehnološka dimenzija obuhvaća interne i eksterne karakteristike tehnološke dostupnosti za poduzeće, organizacijska pak odnose, procese i ostale organizacijske mehanizme poduzeća, a dimenzija okruženja tržišne karakteristike u kojima poduzeće posluje (Tornatzky i Fleischer, 1990). Obzirom na široku prepoznatost ovog teorijskog okvira u području prihvata različitih tehnoloških inovacija u poduzećima od strane mnogih autora, teorijski okvir Tehnologija - Organizacija - Okruženje primijenjen je i za potrebe istraživanja u ovome radu. 
U svrhu izbora odrednica prihvata sustava poslovne inteligencije prema dimenzijama izabranog teorijskog okvira proveden je pregled literature u dvjema bazama znanstvenih radova Web of Science i Scopus, a koje su prepoznate kao najistaknutije i najrelevantnije baze visokokvalitetnih znanstvenoistraživačkih radova (Aghaei Chadegani i sur., 2013; Nacionalno vijeće za znanost, visoko obrazovanje i tehnološki razvoj, 2017). Strategija pretrage literature prikazana je Tablicom 1.

Tablica 1. Strategija pregleda literature na temu prihvata tehnoloških inovacija u sklopu teorijskog okvira Tehnologija - Organizacija - Okruženje

\begin{tabular}{|c|c|c|}
\hline \multicolumn{3}{|c|}{ Strategija pregleda literature } \\
\hline Baza znanstvenih radova & Web of Science & Scopus \\
\hline Ključne riječi: & $\begin{array}{l}\text { (TS=("Technology Organi- } \\
\text { zation Environment Frame- } \\
\text { work" OR "TOE frame- } \\
\text { work") AND TS=("adop- } \\
\text { tion" AND "technological } \\
\text { innovation")) }\end{array}$ & $\begin{array}{l}\text { TITLE-ABS-KEY ("Tech- } \\
\text { nology Organization Envi- } \\
\text { ronment Framework" OR } \\
\text { "TOE framework") AND } \\
\text { TITLE-ABS-KEY ("adop- } \\
\text { tion" AND "technological } \\
\text { innovation") }\end{array}$ \\
\hline \multicolumn{3}{|l|}{ Ograničenja pretraživanja: } \\
\hline Jezik: & Engleski & Engleski \\
\hline Godine publikacije: & Do 2020. godine & Do 2020. godine \\
\hline
\end{tabular}

Izvor: istraživanje autora prema Web of Science i Scopus bazi znanstvenih radova, 2020.

Izvršeni pregled literature rezultirao je s ukupno dvadeset osam radova iz obje istražene baze pri čemu je osamnaest radova bilo iz Scopus baze, a deset iz baze znanstvenih radova Web of Science. Nakon što su svi radovi detaljno pročitani i analizirani, izuzeto je ukupno deset radova od čega se osam radova pojavilo u obje baze, jedan nije bio napisan na engleskom jeziku, a jedan se nije doticao izabrane teme istraživanja. Preostali radovi analizirani su obzirom na njihovo područje i godinu publikacije. Najviše radova objavljeno je iz područja poslovne ekonomije i računalnih znanosti dok se analizom godina publikacije primjećuje rast interesa u znanstvenim krugovima za istraživanjem prihvata tehnoloških inovacija u okviru odrednica teorijskog okvira Tehnologija - Organizacija - Okruženje.

Radovi su potom detaljno analizirani u svrhu pronalaska odrednica koje se koriste za prihvat tehnoloških inovacija u okvirima triju dimenzija odabranog teorijskog okvira. Prema dobivenim rezultatima o učestalosti pojavljivanja odrednica u analiziranim radovima odabrane su sljedeće odrednice za svaku od triju dimenzija okvira Tehnologija - Organizacija - Okruženje:

1. Tehnološka dimenzija: Percepcija komparativne prednosti, Kompleksnost sustava poslovne inteligencije, Kompatibilnost sustava poslovne inteligencije i Mogućnost procjene koristi sustava poslovne inteligencije

2. Organizacijska dimenzija: Organizacijska podrška, Organizacijska spremnost i Kvaliteta upravljanja podacima kao podrška donošenju odluka

3. Dimenzija okruženja: Pritisak konkurencije i Kvaliteta proizvođača i/ili ponuditelja softvera sustava poslovne inteligencije. 
Sukladno prethodnim istraživanjima te specifičnostima primjene sustava poslovne inteligencije kao i karakteristikama malih i srednjih poduzeća tercijarnoga sektora Republike Hrvatske, definirane su i tvrdnje koje ispituju svaku od prethodno izabranih odrednica prihvata za prihvat sustava poslovne inteligencije u malim i srednjim poduzećima tercijarnoga sektora na području Republike Hrvatske.

Unutar tehnološke dimenzije percepcija komparativne prednosti ispituje troškovnu i vremensku dimenziju sustava poslovne inteligencije, njegovu učinkovitost u procesu donošenja odluka, poduzimanju strateških akcija, svakodnevnom funkcioniranju i nadzora poslovanja (Elbashir, Collier i Davern, 2008; Wang, Wang i Yang, 2010; Ifinedo, 2011; Rostek, 2013; Boonsiritomachai, 2014 prema Chaveesuk, 2010; Moore i Benbasat, 1991; Puklavec, Oliveira i Popovič, 2018 prema Chong i Chan, 2012; Oliveira Thomas i Espadanal, 2014). Odrednica kompleksnosti sustava poslovne inteligencije prema autorima Zhu i Kraemer (2005), Wang, Wang i Yang, 2010; Ifinedo (2011), Rostek (2013), Boonsiritomachai (2014) prema Chaveesuk (2010), Moore i Benbasat (1991), Salleh i Jancezwski (2016) i Pathan i sur. (2017) istražuje kompleksnost pri upoznavanju s radom sustava, uvođenju sustava u poslovanje, njegovoj primjeni, daljnjem usavršavanju njegove primjene te posljedični otpor zaposlenika pri njegovom korištenju. Treća odrednica po redu, kompatibilnost sustava poslovne inteligencije obuhvaća ispitivanje usklađenosti sustava poslovne inteligencije s poslovnim pravilima/vrijednostima, poslovnom praksom te infrastrukturom i tehnologijama koju poduzeće posjeduje (Ghobakhloo, Arias-Aranda i Benitez-Amado, 2011; Ifinedo, 2011; Rostek, 2013; Boonsiritomachai, 2014 prema Chaveesuk, 2010; Moore i Benbasat, 1991; Gangwar, Date i Ramaswamy, 2015; Salleh i Jancezwski, 2016; Pathan i sur., 2017). Posljednja odrednica tehnološke dimenzije unutar mogućnosti procjene koristi sustava poslovne inteligencije ispituje razinu zaposlenikova znanja i upoznatosti s radom sustava poslovne inteligencije prije njegova prihvata, razumljivosti njegovih koristi od prihvata te upoznatosti s njegovom primjenom izvan okvira poduzeća u kojem rade (Rostek, 2013; Boonsiritomachai, 2014 prema Park i Chen, 2007; Moore i Benbasat, 1991; Olexova, 2014).

Organizacijska podrška je prva izabrana odrednica unutar organizacijske dimenzije, a koja prema autorima Premkumar i Roberts (1999), Meyer (2000), Yeoh i Koronios (2010), Oliveira Thomas i Espadanal (2014), Pathan i sur. (2017), Puklavec, Oliveira i Popovič, (2018) prema Chong i Chan (2012) te Gu, Cao i Duan (2012) istražuje potporu vrhovnog menadžmenta pri prihvatu sustava u poslovanje poduzeća i njegovu spremnost na preuzimanje rizika od neuspješnog prihvata te potporu ,projekt šampiona“ koji će inicirati, zagovarati i isticati koristi koje sustav poslovne inteligencije može ostvarivati za poduzeće. Sljedeća odrednica organizacijske dimenzije je organizacijska spremnost, a koja se temelji na istraživanju razine razumijevanja, znanja te potrebnim vještinama za upotrebu sustava poslovne inteligencije te primjerene razine organizacijskih resursa nužnih za provedbu projekta prihvata sustava poslovne inteligencije u poduzeću (Ifinedo, 2011; Boonsiritomachai, 2014 prema Chaveesuk, 2010, Iacovou, Benbasat i Dexter, 1995, Gangwar, Date i Ramaswamy, 2015; Puklavec, Oliveira i Popovič, 2018). Zadnja odrednica organizacijske dimenzije istražuje definiranost, pouzdanost podataka te primjenu kvantitativnih analiza podataka pri donošenju poslovnih odluka (Wixom i Watson, 2001; Ramamurthy, Sen i Sinha, 2008; Cheng i Cheng, 2011; Olexova, 2014; Puklavec, Oliveira i Popovič, 2018 prema Kulkarni, Robles-Flores i Popovič, 2017). 
Dimenzija okruženja obuhvaća dvije odrednice od kojih prva istražuje pritisak konkurencije, odnosno razinu pritiska konkurenata poduzeća na prihvat sustava poslovne inteligencije kroz njihovu prethodnu primjenu razmatranog sustava, osvješćivanje o nužnosti i strateškoj važnosti primjene sustava u poslovanju promatranog poduzeća radi vlastite održivosti na tržištu (Pirttimaki, 2007; Wang, Wang i Yang, 2010; Ifinedo, 2011; Rostek, 2013; Boonsiritomachai, 2014 prema Grandon i Pearson, 2004; Hwang i sur., 2004). Druga odrednica organizacijske dimenzije te ujedno i posljednja odrednica istraživanja u prihvatu sustava poslovne inteligencije za tercijarna mala i srednja poduzeća Republike Hrvatske je kvaliteta proizvođača i/ili ponuditelja softvera sustava poslovne inteligencije, a koja istražuje važnost ugleda, kompetentnosti, sposobnosti, podrške i promocije proizvođača i/ili ponuditelja softvera sustava poslovne inteligencije na hrvatskom tržištu (Premkumar i Roberts, 1999, Kumar, Maheshwari i Kumar, 2002; Aruthari i Hasan, 2005; Kaur i Mahanti, 2008; Karsak i Ozogul, 2009; Liao i sur., 2010; Rostek, 2013; Boonsiritomachai, 2014 prema Chaveesuk, 2010; Hwang i sur., 2004; Khan i Faisal, 2015; Soloukdar i Parpanchi, 2015; Puklavec, Oliveira i Popovič, 2018).

\section{METODOLOGIJA}

\subsection{Karakteristike provedenog istraživanja}

Za potrebe ovog istraživanja provedeno je anketno ispitivanje na definiranom uzorku malih i srednjih poduzeća na području Republike Hrvatske. U obzir su uzeta samo poduzeća koja obavljaju djelatnosti koje potpadaju pod djelatnosti tercijarnoga odnosno uslužnoga sektora. Sukladno definiciji Zakona o računovodstvu (2019) za mala i srednja poduzeća

Slika 1. Model istraživanja

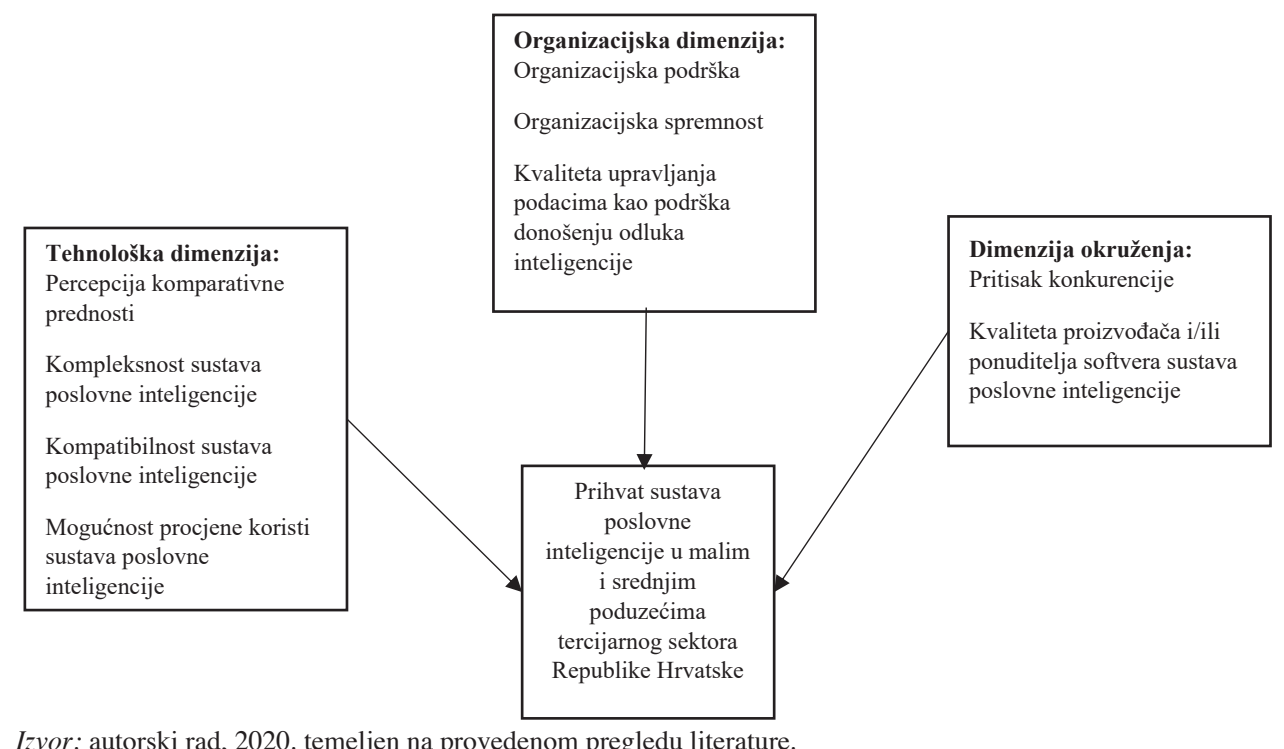

Izvor: autorski rad, 2020. temeljen na provedenom pregledu literature. 
Tablica 2. Varijable istraživanja

1. Tehnološka dimenzija_TD

TD1_Percepcija komparativne prednosti

TD1_1 Korištenje BIS-a omogućuje izbjegavanje nepotrebnih troškova i uštedu na vremenu.

TD1_2 Troškovna učinkovitost BIS-a veća je nego kod drugih sustava (softvera) za potporu odlučivanju.

TD1_3 Uporaba BIS-a omogućuje donošenje kvalitetnijih odluka.

TD1_4 Uporaba BIS-a omogućuje brže obavljanje akcija i odlučivanje.

TD1_5 Uporaba BIS-a omogućuje jednostavnije obavljanje poslovnih zadataka.

TD1_6 Uporaba BIS-a omogućuje veću kontrolu nad poslovanjem

TD2_Kompleksnost sustava poslovne inteligencije

TD2_1 Proces upoznavanja s radom BIS-a bio je složen.

TD2_2 Proces uvođenja BIS-a bio je složen.

TD2_3 Korištenje BIS-a je složeno i zahtjevno za korisnike.

TD2_4 Bilo je teško naučiti kako raditi s BIS-om.

TD2_5 Otpor korištenju BIS-a posljedica je složenosti rada s BIS-om.

TD3_Kompatibilnost sustava poslovne inteligencije

TD3_1 Uporaba BIS-a je kompatibilna s postojećim poslovnim vrijednostima i uvjerenjima (ciljevi i zadaci sustava podupiru misiju, viziju i ciljeve poslovanja).

TD3_2 Promjene nastale prihvaćanjem BIS-a su kompatibilne s postojećom poslovnom praksom (npr. procesi, procedure, organizacijska struktura, strateški ciljevi).

TD3_3 BIS je kompatibilan s postojećom tehnološkom infrastrukturom.

TD3_4 BIS je povezan s našim informacijskim sustavima, programskim alatima i programskim rješenjima.

TD4_Mogućnost procjene koristi sustava poslovne inteligencije

TD4_1 Zaposlenici su bili upoznati s očekivanim rezultatima uvođenja BIS-a prije pokretanja projekta njegovog uvođenja.

TD4_2 Za zaposlenike, koristi od primjene BIS-a su jasne i lako mjerljive.

TD4_3 Zaposlenici su bili upoznati s postojanjem BIS-a na tržištu softvera.

TD4_4 Zaposlenici su imali priliku vidjeti da se BIS koristi u drugim poduzećima. 2. Organizacijska dimenzija_OD

OD1_Organizacijska podrška

OD1_1 Top menadžment podržava primjenu i podupire prihvaćanje BIS-a.

OD1_2 Top menadžment aktivno sudjeluje u uspostavljanju vizije i oblikovanju strategije prihvaćanja BIS-a.

OD1_3 Top menadžment je spreman preuzeti rizike koje donosi uvođenje i korištenje BIS-a.

OD1_4 Postoji osoba na razini menadžmenta koja snažno zagovara primjenu BIS-a (upozorava na važnost primjene sustava).

OD1_5 Postoji osoba na razini menadžmenta koja pokazuje veliki entuzijazam u iniciranju prihvaćanja BIS-a (motivira na prihvaćanje sustava).

OD1_6 Postoji jedna ili više osoba na razini menadžmenta koja konstantno ističe prednosti BIS-a. 
OD2_Organizacijska spremnost

OD2_1 Menadžeri i zaposlenici znaju kako koristiti IT za potporu poslovanju.

OD2_2 Menadžeri i zaposlenici dobro razumiju kako koristiti BIS u poslovanju.

OD2_3 Posjedujemo dovoljno tehničkih, upravljačkih i ostalih vještina potrebnih za prihvaćanje BIS-a.

OD2_4 Posjedujemo dovoljno financijskih, tehnoloških i ostalih resursa potrebnih za prihvaćanje BIS-a.

OD3_Kvaliteta upravljanja podacima kao podrška donošenju odluka

OD3_1 Podaci koje trenutno koristimo u poslovanju su pouzdani.

OD3_2 Postoji dogovor o jasno definiranim poslovnim pravilima i skupu definicija o podacima.

OD3_3 Potiče se traženje i korištenje podataka/informacija kojima će se podržati donošenje odluka.

OD3_4 Potiču se procesi u donošenju odluka koji uključuju kvantitativne/numeričke analize.

3. Dimenzija okruženja_DO

DO1_Pritisak konkurencije

DO1_1 Stupanj konkurencije u našoj djelatnosti doveo je do pritiska koji je utjecao na odluku o nužnosti prihvaćanju BIS-a.

DO1_2 Naše poduzeće je moralo početi koristiti BIS kako bi zadržalo svoju konkurentsku prednost na tržištu.

DO1_3 Svjestan/na sam da konkurenti već koriste BIS u svom poslovanju.

DO1_4 Za naše poduzeće, bilo je strateški nužno započeti s uporabom BIS-a.

DO2_Kvaliteta proizvođača i/ili ponuditelja softvera sustava poslovne inteligencije

DO2_1 Reputacija proizvođača i/ili ponuditelja softvera je bitna prilikom izbora BIS-a.

DO2_2 Tehnološke kompetencije proizvođača softvera su bitne prilikom izbora BIS-a.

DO2_3 Sposobnost proizvođača i/ili ponuditelja BIS-a da uspješno provede projekt uvođenja BIS-a nam je važna prilikom izbora.

DO2_4 Važno nam je da proizvođač i/ili ponuditelj BIS-a po završetku projekta uvođenja pruža potporu njegovom korištenju.

DO2_5 Proizvođači i/ili ponuditelji softvera promoviraju BIS nudeći besplatne sate edukacije.

Izvor: autorski rad, 2020. prema Elbashir, Collier i Davern, 2008; Wang, Wang i Yang, 2010; Ifinedo, 2011; Rostek, 2013; Boonsiritomachai, 2014; Chaveesuk, 2010; Moore i Benbasat, 1991; Puklavec, Oliveira i Popovič, 2018; Chong i Chan, 2012; Oliveira Thomas i Espadanal, 2014; Zhu i Kraemer (2005), Salleh i Jancezwski, 2016; Pathan i sur. 2017; Ghobakhloo, Arias-Aranda i Benitez-Amado, 2011; Gangwar, Date i Ramaswamy, 2015; Park i Chen, 2007; Olexova, 2014; Premkumar i Roberts, 1999; Meyer, 2000; Yeoh i Koronios, 2010; Gu, Cao i Duan, 2012; Iacovou, Benbasat i Dexter, 1995, Wixom i Watson, 2001; Ramamurthy, Sen i Sinha, 2008; Cheng i Cheng, 2011; Kulkarni, Robles-Flores i Popovič, 2017; Pirttimaki, 2007; Grandon i Pearson, 2004; Hwang i sur., 2004; Kumar, Maheshwari i Kumar, 2002; Aruthari i Hasan, 2005; Kaur i Mahanti, 2008; Karsak i Ozogul, 2009; Liao i sur., 2010; Khan i Faisal, 2015; Soloukdar i Parpanchi, 2015 
u Republici Hrvatskoj, obuhvaćena su sva poduzeća koja imaju više od 10 zaposlenika i manje od 251 zaposlenika te ostvaruju više od 5,2 milijuna kuna i manje od 300 milijuna kuna na godišnjoj razini.

Upitnik je formiran sukladno prethodno definiranim odrednicama svake dimenzije odabranog teorijskog okvira, a pitanja su bila usmjerena ciljanim ispitanicima kao što su top menadžment poduzeća ili pak informatički ili stručnjaci za sustave poslovne inteligencije. Istraživanju se ukupno odazvalo 110 malih i srednjih poduzeća, od čega je 100 odgovora bilo valjano i relevantno za daljnju analizu.

Varijable istraživanja definirane su sukladno prethodno odabranim odrednicama unutar tehnološke, organizacijske i dimenzije okruženja primijenjenog teorijskog okvira Tehnologija - Organizacija - Okruženje. Tablicom 2 prikazane su promatrane istraživačke varijable unutar svake dimenzije. Na temelju postavljenih odrednica, Slikom 1 prikazan je model istraživanja odrednica utjecaja unutar dimenzija okvira Tehnologija - Organizacija - Okruženje na prihvat sustava poslovne inteligencije u malim i srednjim poduzećima tercijarnoga sektora na području Republike Hrvatske.

\subsection{Faktorska analiza}

Provedba faktorske analize u svrhu identifikacije potencijalno izabranih odrednica prihvata dodijeljenih svakoj od triju dimenzija teorijskog okvira Tehnologija - Organizacija - Okruženje te u cilju testiranja primjenjivosti odabranog okvira za prihvat sustava poslovne inteligencije u malim i srednjim poduzećima tercijarnoga sektora Republike Hrvatske. Prema dobivenim rezultatima temeljenim na podacima istraživanja o karakteristikama poduzeća, u istraživanju su najviše sudjelovala poduzeća s područja informacijsko-komunikacijskih djelatnosti, trgovine na veliko i malo, stručnih, znanstvenih i tehničkih djelatnosti, financijskim i djelatnostima osiguranja.

U prvom koraku je provjerena adekvatnost prikupljenih podataka za provedbu faktorske analize uz pomoć izračuna Kaiser-Meyer-Olikonova testa pri čemu su izračunate vrijednosti za sve tri dimenzije veće od granične vrijednosti testa koja iznosi 0,5 (Hill, 2011). Time se ukazuje na pogodnost uzorkovanih podataka svih triju dimenzija na provedbu faktorske analize. Rezultati provedenog testa za sve tri dimenzije teorijskog okvira Tehnologija - Organizacija - Okruženje prikazani su Tablicom 3.

Tablica 3. Kaiser - Meyer - Olkinov test faktorske analize za tehnološku, organizacijsku i dimenziju okruženja

\begin{tabular}{|l|c|}
\hline Dimenzija teorijskog okvira Tehnologija - Organizacija - Okruženje & $\begin{array}{c}\text { Kaiser-Mey- } \\
\text { er-Olkin test }\end{array}$ \\
\hline Tehnološka dimenzija okvira Tehnologija - Organizacija - Okruženje & 0,760 \\
\hline Organizacijska dimenzija okvira Tehnologija - Organizacija - Okruženje & 0,883 \\
\hline Dimenzija okruženja okvira Tehnologija - Organizacija - Okruženje & 0,883 \\
\hline
\end{tabular}

Izvor: autorski rad, 2019. 
U drugom koraku proveden je Bartlett'sov test sfericiteta nad svakom dimenzijom teorijskoga okvira Tehnologija - Organizacija - Okruženje u svrhu utvrđivanja značajnosti korelacijske matrice. Prema dobivenim rezultatima prikazanim Tablicom 4, sve tri dimenzije sadrže podatke pogodne za faktorizaciju obzirom da su se sva tri testa pokazala značajnim uz razinu statističke značajnosti od $1 \%$.

Tablica 4. Bartlettsov test sfericiteta faktorske analize za tehnološku, organizacijsku i dimenziju okruženja

\begin{tabular}{|l|c|c|}
\hline Dimenzija teorijskog okvira & \multicolumn{2}{|c|}{ Bartlett'sov test sfericiteta } \\
\hline \multirow{2}{*}{$\begin{array}{l}\text { Tehnologija - Organizacija - Okruženje } \\
\text { Tehnologija dimenzija okvira }\end{array}$} & $\begin{array}{c}\text { Approx. Chi-Square } \\
\text { df }\end{array}$ & 963,084 \\
& Sig. & 171 \\
& $0,000^{* * *}$ \\
\hline \multirow{2}{*}{$\begin{array}{l}\text { Organizacijska dimenzija okvira } \\
\text { Tehnologija - Organizacija - Okruženje }\end{array}$} & Approx. Chi-Square & 935,531 \\
\cline { 2 - 3 } & Df & 91 \\
\cline { 2 - 3 } & Sig. & $0,000^{* * *}$ \\
\hline \multirow{2}{*}{$\begin{array}{l}\text { Dimenzija okruženja okvira } \\
\text { Tehnologija - Organizacija - Okruženje }\end{array}$} & Approx. Chi-Square & 508,939 \\
\cline { 2 - 3 } & Df & 36 \\
\cline { 2 - 3 } & Sig. & $0,000^{* * *}$ \\
\hline
\end{tabular}

Izvor: autorski rad, 2019.

Napomena: $* * *$ Statistički značajno uz $1 \%$.

Sljedećim tabličnim prikazima, predstavljeni su rezultati faktorske analize komponenata provedene za sve tri dimenzije teorijskog okvira Tehnologija - Organizacija - Okruženje u sklopu kojih su dani rezultati svojstvenih vrijednosti, individualnih te kumulativni postotci varijance. Ukoliko je svojstvena vrijednost faktora veća od 1 on se izlučuje odnosno uzima se u obzir (Kiss, 2011). Shodno tome, zaključujemo kako se unutar tehnološke dimenzije mogu izlučiti četiri faktora (Tablica 5), unutar organizacijske tri (Tablica 6), a unutar dimenzije okruženja dva faktora s svojstvenim vrijednostima većim od 1 (Tablica 7). Prema tome, možemo zaključiti i kako je prvotni odabir odrednica unutar svake dimenzije potvrđen rezultatima prikazanih svojstvenih vrijednosti.

Tablica 5. Faktorske analize komponenata tehnološke dimenzije teorijskog okvira Tehnologija - Organizacija - Okruženje

\begin{tabular}{|c|c|c|c|}
\hline \multirow{2}{*}{$\begin{array}{c}\text { Tehnološka } \\
\text { dimenzija }\end{array}$} & \multicolumn{3}{|c|}{ Initial Eigenvalues } \\
\cline { 2 - 4 } & $\begin{array}{c}\text { Svojstvena } \\
\text { vrijednost }\end{array}$ & Postotak varijance & $\begin{array}{c}\text { Kumulativni posto- } \\
\text { tak varijance }\end{array}$ \\
\hline TD1_1 & $\mathbf{5 , 0 4 1}$ & 26,532 & 26,532 \\
\hline TD1_2 & $\mathbf{3 , 2 8 9}$ & 17,312 & 43,844 \\
\hline TD1_3 & $\mathbf{2 , 1 6 1}$ & 11,373 & 55,217 \\
\hline TD1_4 & $\mathbf{1 , 8 6 7}$ & 9,825 & 65,042 \\
\hline TD1_5 & 0,997 & 5,246 & 70,288 \\
\hline TD1_6 & 0,839 & 4,417 & 74,705 \\
\hline
\end{tabular}




\begin{tabular}{|c|c|c|c|}
\hline \multirow{2}{*}{$\begin{array}{c}\text { Tehnološka } \\
\text { dimenzija }\end{array}$} & $\begin{array}{c}|c| \\
\text { Svojstvena } \\
\text { vrijednost }\end{array}$ & Postotak varijance & $\begin{array}{c}\text { Kumulativni posto- } \\
\text { tak varijance }\end{array}$ \\
\cline { 2 - 4 } & 0,697 & 3,670 & 78,375 \\
\hline TD2_1 & 0,656 & 3,452 & 81,827 \\
\hline TD2_2 & 0,555 & 2,921 & 84,749 \\
\hline TD2_3 & 0,502 & 2,643 & 87,392 \\
\hline TD2_4 & 0,422 & 2,220 & 89,612 \\
\hline TD2_5 & 0,398 & 2,093 & 91,705 \\
\hline TD3_1 & 0,319 & 1,680 & 93,385 \\
\hline TD3_2 & 0,270 & 1,423 & 94,808 \\
\hline TD3_3 & 0,258 & 1,357 & 96,165 \\
\hline TD3_4 & 0,217 & 1,140 & 97,305 \\
\hline TD4_1 & 0,197 & 1,039 & 98,344 \\
\hline TD4_2 & 0,173 & 0,912 & 99,255 \\
\hline TD4_3 & 0,141 & 0,745 & 100,000 \\
\hline TD4_4 & & & \\
\hline
\end{tabular}

Izvor: autorski rad, 2019.

Tablica 6. Faktorske analize komponenata organizacijske dimenzije teorijskog okvira Tehnologija Organizacija - Okruženje

\begin{tabular}{|c|c|c|c|}
\hline \multirow{2}{*}{$\begin{array}{c}\text { Organizacijska di- } \\
\text { menzija }\end{array}$} & $\begin{array}{c}|c| \\
\text { Svojstvena } \\
\text { vrijednost }\end{array}$ & Postotak varijance & $\begin{array}{c}\text { Kumulativni posto- } \\
\text { tak varijance }\end{array}$ \\
\hline OD1_1 & $\mathbf{7 , 0 9 2}$ & 50,654 & 50,654 \\
\hline OD1_2 & $\mathbf{1 , 7 4 8}$ & 12,483 & 63,136 \\
\hline OD1_3 & $\mathbf{1 , 1 3 0}$ & 8,069 & 71,206 \\
\hline OD1_4 & 0,778 & 5,554 & 76,759 \\
\hline OD1_5 & 0,622 & 4,446 & 81,205 \\
\hline OD1_6 & 0,552 & 3,942 & 85,148 \\
\hline OD2_1 & 0,447 & 3,193 & 88,341 \\
\hline OD2_2 & 0,339 & 2,422 & 90,763 \\
\hline OD2_3 & 0,303 & 2,161 & 92,924 \\
\hline OD2_4 & 0,245 & 1,752 & 94,676 \\
\hline OD3_1 & 0,233 & 1,664 & 96,340 \\
\hline OD3_2 & 0,218 & 1,556 & 97,896 \\
\hline OD3_3 & 0,171 & 1,219 & 99,115 \\
\hline OD3_4 & 0,124 & 0,885 & 100,000 \\
\hline
\end{tabular}

Izvor: autorski rad, 2019. 
Tablica 7. Faktorske analize komponenata dimenzije okruženja teorijskog okvira Tehnologija - Organizacija Okruženje

\begin{tabular}{|l|r|r|r|}
\hline \multirow{2}{*}{$\begin{array}{l}\text { Dimenzija } \\
\text { okruženja }\end{array}$} & \multicolumn{3}{|c|}{ Initial Eigenvalues } \\
\cline { 2 - 4 } & $\begin{array}{c}\text { Svojstvena } \\
\text { vrijednost }\end{array}$ & $\begin{array}{c}\text { Postotak } \\
\text { varijance }\end{array}$ & $\begin{array}{c}\text { Kumulativni } \\
\text { postotak } \\
\text { varijance }\end{array}$ \\
\hline DO1_1 & $\mathbf{4 , 4 8 7}$ & 49,855 & 49,855 \\
\hline DO1_2 & $\mathbf{1 , 6 3 8}$ & 18,204 & 68,059 \\
\hline DO1_3 & 0,893 & 9,918 & 77,976 \\
\hline DO1_4 & 0,557 & 6,184 & 84,160 \\
\hline DO2_1 & 0,478 & 5,311 & 89,471 \\
\hline DO2_2 & 0,307 & 3,413 & 92,884 \\
\hline DO2_3 & 0,286 & 3,179 & 96,063 \\
\hline DO2_4 & 0,196 & 2,183 & 98,246 \\
\hline DO2_5 & 0,158 & 1,754 & 100,000 \\
\hline
\end{tabular}

Izvor: autorski rad, 2019.

U narednim prikazima Catellijevih dijagrama grafičkim putem su prikazane faktorske analize komponenata za svaku od navedenih triju dimenzija odabranog teorijskog okvira Tehnologija - Organizacija - Okruženje.

Grafikonom 1. lako je za uočiti kako se unutar tehnološke dimenzije vizualno izdvajaju svojstvene vrijednosti spomenuta četiri faktora od svojstvenih vrijednosti ostalih fak-

Grafikon 1. Catellijev dijagram faktorske analize komponenata za tehnološku dimenziju teorijskog okvira Tehnologija - Organizacija - Okruženje

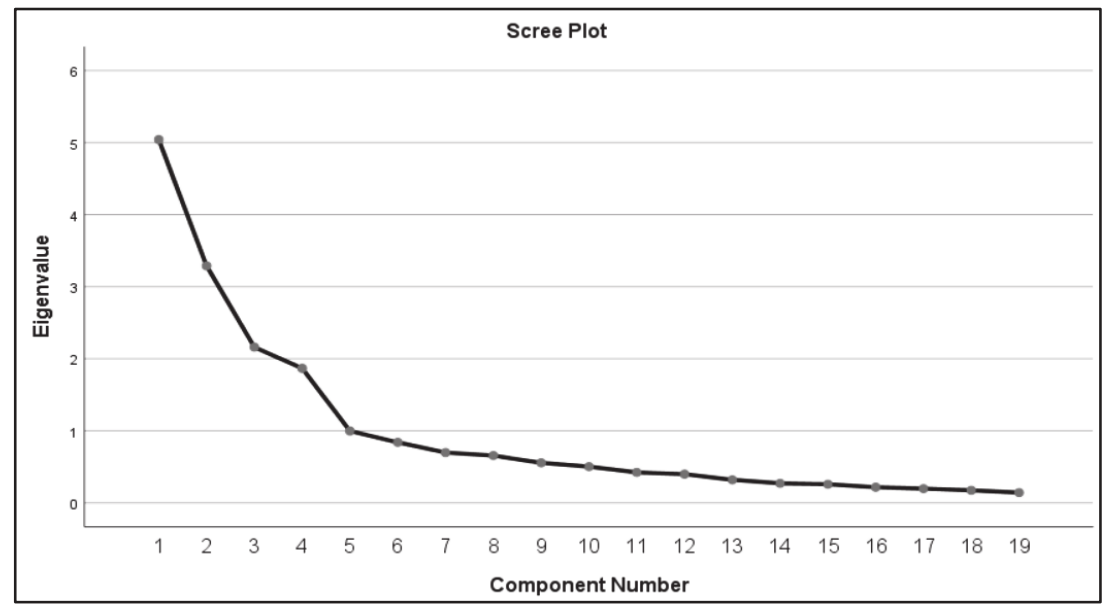

Izvor: autorski rad, 2019. 
Grafikon 2. Catellijev dijagram faktorske analize komponenata za organizacijsku dimenziju teorijskog okvira Tehnologija - Organizacija - Okruženje

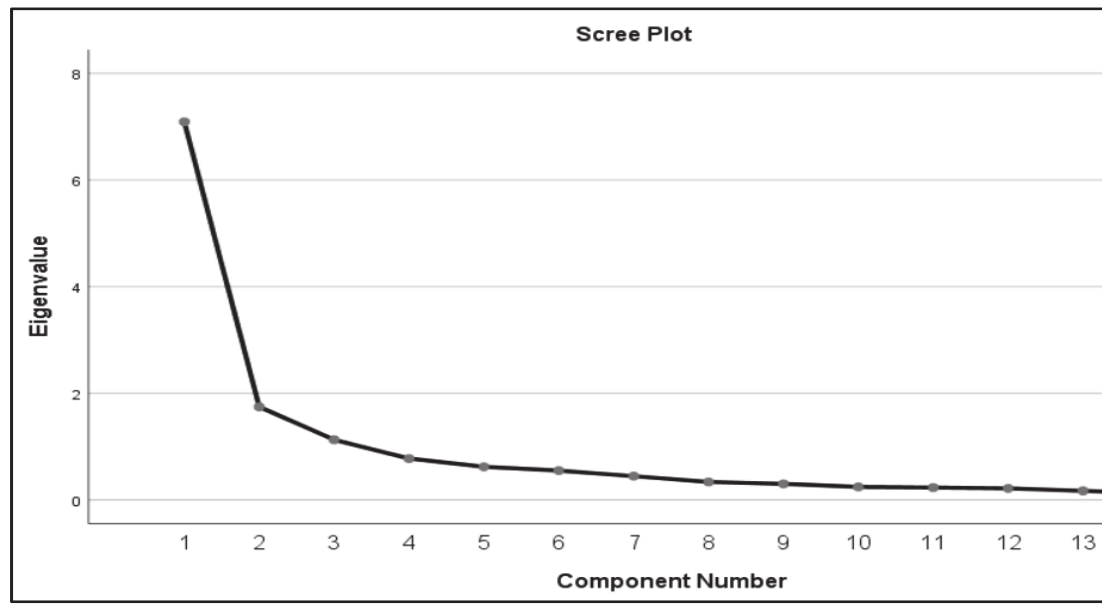

Izvor: autorski rad, 2019.

Grafikon 3. Catellijev dijagram faktorske analize komponenata za dimenziju okruženja teorijskog okvira Tehnologija - Organizacija - Okruženje

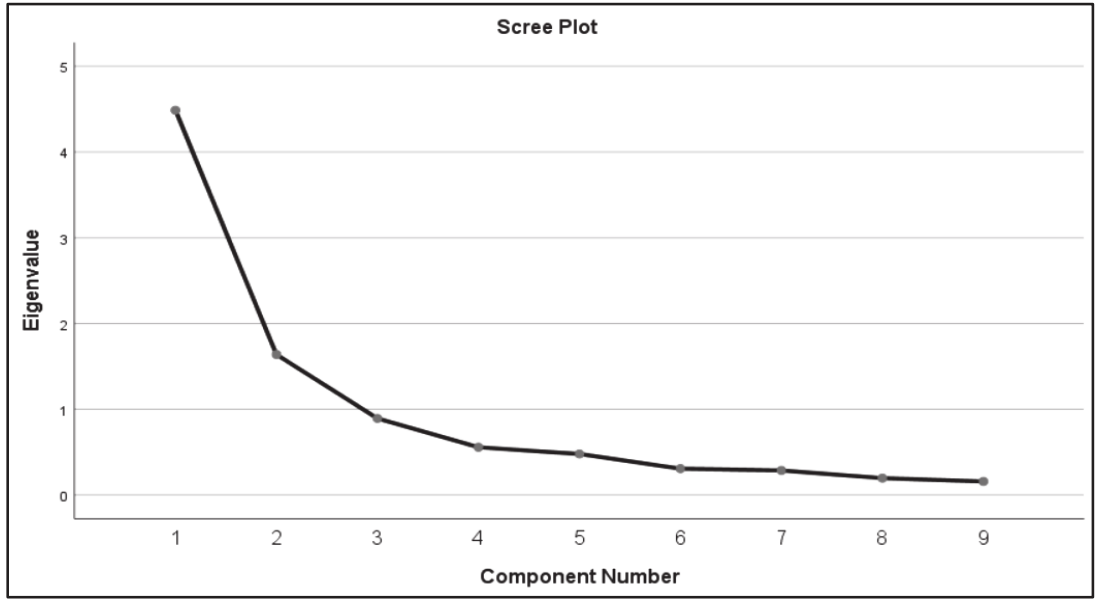

Izvor: autorski rad, 2019.

tora iste dimenzije. Grafičkim prikazom faktorske analize komponenata za organizacijsku dimenziju uočava se izdvajanje svojstvenih vrijednosti spomenuta tri faktora za razliku od ostalih svojstvenih vrijednosti faktora unutar organizacijske dimenzije (Grafikon 2). Grafikonom 3 prikazane su svojstvene vrijednosti faktora dimenzije okruženja, pri čemu se lako uočava izdvajanje svojstvenih vrijednosti prvih dvaju faktora od preostalih faktora iste dimenzije teorijskog okvira Tehnologija - Organizacija - Okruženje. 
Matrica faktorske strukture nakon Varimax rotacije faktora za varijable tehnološke, organizacijske i dimenzije okruženja prikazana je Tablicom 8 . Rezultati vrijednosti faktora većih od granične vrijednosti 0,5 ukazuju na izlučivanje četiri faktora unutar tehnološke dimenzije čime se potvrđuju dobiveni rezultati faktorske analize komponenata za tehnološku dimenziju prikazani Tablicom 5 i Grafikonom 1. Rezultati faktorske analize komponenata organizacijske dimenzije prikazani Tablicom 6 i Grafikonom 2, potvrđuju se prikazom rezultata matrice faktorske strukture nakon Varimax rotacije faktora za varijable organizacijske dimenzije (Tablica 8) pri čemu se izdvajaju tri faktora s rezultatima vrijednosti većima od granične vrijednosti 0,5 . Tablicom 8 prikazana je i matrica faktorske strukture nakon Varimax rotacije faktora za varijable dimenzije okruženja pri čemu se uočava izdvajanje dva faktora s vrijednostima faktora većima od granične vrijednosti 0,5 . Ovaj rezultat izlučenih faktora dimenzije okruženja također potvrđuje rezultate faktorske analize komponenata za dimenziju okruženja prikazane Tablicom 7 i Grafikonom 3.

Tablica 8. Matrica faktorske strukture nakon Varimax rotacije faktora komponenata - tehnološka, organizacijska i dimenzija okruženja

\begin{tabular}{|l|r|r|r|r|}
\hline Tehnološka dimenzija & Faktor 1 & Faktor 2 & Faktor 3 & Faktor 4 \\
\hline TD1_1 & $\mathbf{0 , 6 4 2}$ & $-0,139$ & 0,300 & 0,220 \\
\hline TD1_2 & $\mathbf{0 , 5 8 4}$ & 0,170 & 0,126 & $-0,023$ \\
\hline TD1_3 & $\mathbf{0 , 8 6 1}$ & $-0,076$ & 0,097 & 0,038 \\
\hline TD1_4 & $\mathbf{0 , 8 2 7}$ & $-0,079$ & 0,025 & 0,157 \\
\hline TD1_5 & $\mathbf{0 , 6 0 1}$ & $-0,016$ & 0,018 & 0,404 \\
\hline TD1_6 & $\mathbf{0 , 7 7 8}$ & 0,007 & 0,203 & $-0,004$ \\
\hline TD2_1 & 0,097 & $\mathbf{0 , 8 0 7}$ & $-0,121$ & 0,055 \\
\hline TD2_2 & 0,122 & $\mathbf{0 , 7 6 4}$ & $-0,085$ & 0,016 \\
\hline TD2_3 & 0,004 & $\mathbf{0 , 8 5 7}$ & $-0,079$ & 0,068 \\
\hline TD2_4 & $-0,130$ & $\mathbf{0 , 8 1 1}$ & 0,077 & $-0,048$ \\
\hline TD2_5 & $-0,154$ & $\mathbf{0 , 7 1 2}$ & $-0,068$ & 0,044 \\
\hline TD3_1 & 0,233 & $-0,043$ & $\mathbf{0 , 8 2 6}$ & 0,022 \\
\hline TD3_2 & 0,239 & $-0,109$ & $\mathbf{0 , 7 7 0}$ & 0,207 \\
\hline TD3_3 & 0,044 & $-0,117$ & $\mathbf{0 , 8 6 3}$ & 0,104 \\
\hline TD3_4 & 0,103 & $-0,016$ & $\mathbf{0 , 7 6 7}$ & 0,158 \\
\hline TD4_1 & 0,160 & 0,035 & 0,163 & $\mathbf{0 , 7 0 3}$ \\
\hline TD4_2 & 0,148 & 0,028 & 0,312 & $\mathbf{0 , 7 5 6}$ \\
\hline TD4_3 & $-0,073$ & 0,059 & 0,068 & $\mathbf{0 , 8 6 3}$ \\
\hline TD4_4 & 0,163 & 0,024 & 0,002 & $\mathbf{0 , 8 0 2}$ \\
\hline Extraction Method: Principal Component Analysis. & & \\
\hline Rotation Method: Varimax with Kaiser Normalization. & & \\
\hline
\end{tabular}




\begin{tabular}{|l|r|r|r|}
\hline Organizacijska dimenzija & Faktor 1 & Faktor 2 & Faktor 3 \\
\hline OD1_1 & $\mathbf{0 , 7 2 0}$ & 0,307 & 0,059 \\
\hline OD1_2 & $\mathbf{0 , 7 0 0}$ & 0,355 & 0,288 \\
\hline OD1_3 & $\mathbf{0 , 7 2 0}$ & 0,333 & 0,246 \\
\hline OD1_4 & 0,834 & 0,110 & 0,216 \\
\hline OD1_5 & $\mathbf{0 , 8 6 4}$ & 0,133 & 0,177 \\
\hline OD1_6 & $\mathbf{0 , 7 9 6}$ & 0,157 & 0,092 \\
\hline OD2_1 & 0,271 & $\mathbf{0 , 8 4 1}$ & 0,222 \\
\hline OD2_2 & 0,281 & $\mathbf{0 , 7 9 2}$ & 0,262 \\
\hline OD2_3 & 0,222 & $\mathbf{0 , 8 4 0}$ & 0,146 \\
\hline OD2_4 & 0,158 & $\mathbf{0 , 6 8 8}$ & 0,320 \\
\hline OD3_1 & 0,248 & 0,173 & $\mathbf{0 , 7 2 1}$ \\
\hline OD3_2 & 0,021 & 0,148 & $\mathbf{0 , 8 4 6}$ \\
\hline OD3_3 & 0,264 & 0,427 & $\mathbf{0 , 7 0 0}$ \\
\hline OD3_4 & 0,358 & 0,354 & $\mathbf{0 , 6 4 8}$ \\
\hline
\end{tabular}

Extraction Method: Principal Component Analysis.

Rotation Method: Varimax with Kaiser Normalization.

\begin{tabular}{|l|r|r|}
\hline Dimenzija okruženja & Faktor 1 & Faktor 2 \\
\hline DO1_1 & 0,136 & $\mathbf{0 , 8 7 6}$ \\
\hline DO1_2 & 0,116 & $\mathbf{0 , 9 0 6}$ \\
\hline DO1_3 & 0,235 & $\mathbf{0 , 7 0 5}$ \\
\hline DO1_4 & 0,269 & $\mathbf{0 , 8 4 1}$ \\
\hline DO2_1 & $\mathbf{0 , 8 0 4}$ & 0,213 \\
\hline DO2_2 & $\mathbf{0 , 8 0 6}$ & 0,252 \\
\hline DO2_3 & $\mathbf{0 , 8 7 2}$ & 0,212 \\
\hline DO2_4 & $\mathbf{0 , 7 7 0}$ & 0,320 \\
\hline DO2_5 & $\mathbf{0 , 5 1 8}$ & 0,003 \\
\hline Extran
\end{tabular}

Extraction Method: Principal Component Analysis.

Rotation Method: Varimax with Kaiser Normalization. 


\section{REZULTATI I DISKUSIJA}

Obzirom na dobivene rezultate faktorske analize prikazane tablicama i grafikonima u prethodnom dijelu, lako se uočava kako je unutar tehnološke, organizacijske i dimenzije okruženja izlučen isti broj varijabli kao početno postavljenih odrednica svake od dimenzija. Posljednjom tablicom iz provedene faktorske analize prikazane su vrijednosti čestica svake varijable unutar svake od triju dimenzija teorijskog okvira Tehnologija - Organizacija Okruženje. Shodno svemu navedenom daju se sljedeći zaključci.

Varijable odnosno odrednice tehnološke, organizacijske i dimenzije okruženja za mjerenje utjecaja prihvata sustava poslovne inteligencije u malim i srednjim poduzećima tercijarnoga sektora Republike Hrvatske prikazane su Tablicom 9 zajedno s pripadajućim vrijednostima svakog izlučenog faktora.

Unutar tehnološke dimenzije izlučena su ukupno četiri faktora, što odgovara prethodno postavljenim odrednicama istoimene dimenzije. Shodno tome, odrednice tehnološke dimenzije za mjerenje utjecaja prihvata sustava poslovne inteligencije u malim i srednjim poduzećima tercijarnoga sektora Republike Hrvatske jesu: (1) Percepcija komparativne prednosti sustava poslovne inteligencije, (2) Kompleksnost sustava poslovne inteligencije, (3) Kompatibilnost sustava poslovne inteligencije, (4) Mogućnosti procjene koristi sustava poslovne inteligencije.

Provedena faktorska analiza rezultirala je izlučivanjem tri faktora iz organizacijske dimenzije odabranog teorijskog okvira Tehnologija - Organizacija - Okruženje. Shodno izlučenim faktorima, odrednice koje ostvaruju potencijalan utjecaj na prihvaćanje sustava poslovne inteligencije u malim i srednjim poduzećima tercijarnoga sektora na području Republike Hrvatske su: (1) Organizacijska podrška, (2) Organizacijska spremnost i (3) Kvaliteta upravljanja podacima kao podrška donošenju odluka.

Faktorskom analizom izlučena su i ukupno dva faktora dimenzije okruženja. Shodno izlučenim faktorima, definiraju se i sljedeće potencijalne odrednice utjecaja za istraživanje prihvata sustava poslovne inteligencije na uzorku malih i srednjih poduzeća Republike Hrvatske u tercijarnom sektoru, kao što su: (1) pritisak konkurencije i (2) kvaliteta proizvođača i/ili ponuditelja softvera sustava poslovne inteligencije.

Osim dobivenih odrednica unutar triju dimenzija teorijskog okvira Tehnologija - Organizacija - Okruženje, a koje mogu ostvarivati potencijalno značajan utjecaj na prihvat sustava poslovne inteligencije u hrvatskim malim i srednjim poduzećima tercijarnoga sektora, rezultati ovog istraživanja pokazuju najbolje i najslabije objašnjenu dimenziju za istraživanje prihvata sustava poslovne inteligencije na izabranom uzorku. Naime, faktorskom analizom dobiveni su i rezultati kumulativnog prosjeka varijance svih izlučenih faktora čime se prikazuje ukupan postotak objašnjenja varijance svake pojedinačne dimenzije pomoću dobivenih faktora. Prema tome, rezultati su pokazali kako je najbolje objašnjena varijanca organizacijske dimenzije s kumulativnim prosjekom varijance sva tri izlučena faktora od 71,2\%. Nakon nje slijedi dimenzija okruženja s ukupnim kumulativnim prosjekom varijance oba izlučena faktora od $68 \%$ te posljednja i najslabije objašnjena dimenzija sa svoja četiri izlučena faktora, tehnološka dimenzija s ukupnim kumulativnim prosjekom varijance od $65 \%$. 
Tablica 9. Prikaz varijabli (odrednica) tehnološke, organizacijske i dimenzije okruženja prema izlučenim faktorima provedene faktorske analize

\begin{tabular}{|c|c|c|c|c|c|}
\hline \multicolumn{2}{|l|}{ Tehnološka dimenzija } & \multicolumn{2}{|l|}{ Organizacijska dimenzija } & \multicolumn{2}{|l|}{ Dimenzija okruženja } \\
\hline TD1 & Vr. & OD1 & Vr. & DO1 & Vr. \\
\hline $\begin{array}{l}\text { TD1_1 Korištenje BIS-a } \\
\text { omogućuje izbjegavanje } \\
\text { nepotrebnih troškova i } \\
\text { uštedu na vremenu. }\end{array}$ & 范 & $\begin{array}{l}\text { OD1_1 Top menadžment } \\
\text { podržava primjenu i podupire } \\
\text { prihvaćanje BIS-a. }\end{array}$ & సิ & $\begin{array}{l}\text { DO1_1 Stupanj konkurenci- } \\
\text { je u našoj djelatnosti doveo } \\
\text { je do pritiska koji je utjecao } \\
\text { na odluku o nužnosti prih- } \\
\text { vaćanja BIS-a. }\end{array}$ & $\begin{array}{l}0 \\
\infty \\
0 \\
0\end{array}$ \\
\hline $\begin{array}{l}\text { TD1_2 Troškovna } \\
\text { učinkovitost BIS-a veća } \\
\text { je nego kod drugih sus- } \\
\text { tava (softvera) za potporu } \\
\text { odlučivanju. }\end{array}$ & 苾 & $\begin{array}{l}\text { OD1_2 Top menadžment } \\
\text { aktivno sudjeluje u uspostavl- } \\
\text { janju vizije i oblikovanju } \\
\text { strategije prihvaćanja BIS-a. }\end{array}$ & $\frac{8}{0}$ & $\begin{array}{l}\text { DO1_2 Naše poduzeće } \\
\text { je moralo početi koristiti } \\
\text { BIS kako bi zadržalo svoju } \\
\text { konkurentsku prednost na } \\
\text { tržištu. }\end{array}$ & \\
\hline $\begin{array}{l}\text { TD1_3 Uporaba BIS-a } \\
\text { omogućuje donošenje } \\
\text { kvalitetnijih odluka. }\end{array}$ & $\begin{array}{l}\overline{0} \\
\infty \\
0\end{array}$ & $\begin{array}{l}\text { OD1_3 Top menadžment je } \\
\text { spreman preuzeti rizike koje } \\
\text { donosi uvođenje i korištenje } \\
\text { BIS. }\end{array}$ & กิ & & $\begin{array}{l}0 \\
8 \\
0 \\
0\end{array}$ \\
\hline $\begin{array}{l}\text { TD1_4 Uporaba BIS-a } \\
\text { omogućuje brže obav- } \\
\text { ljanje akcija i odlučiva- } \\
\text { nje. }\end{array}$ & ָे & $\begin{array}{l}\text { OD1_4 Postoji osoba na razi- } \\
\text { ni menadžmenta koja snažno } \\
\text { zagovara primjenu BIS-a. }\end{array}$ & \begin{tabular}{l}
\multirow{1}{*}{} \\
$\infty$ \\
0 \\
0
\end{tabular} & $\begin{array}{l}\text { DOI_3 Svjestan/na sam da } \\
\text { konkurenti već koriste BIS } \\
\text { u svom poslovanju. }\end{array}$ & $\frac{n}{2}$ \\
\hline $\begin{array}{l}\text { TD1_5 Uporaba BIS-a } \\
\text { omogućuje jednostavnije } \\
\text { obavljanje poslovnih } \\
\text { zadataka. }\end{array}$ & $\begin{array}{l}1 \\
0 \\
0 \\
0\end{array}$ & $\begin{array}{l}\text { OD1_5 Postoji osoba na } \\
\text { razini menadžmenta koja } \\
\text { pokazuje veliki entuzijazam u } \\
\text { iniciranju prihvaćanja BIS-a. }\end{array}$ & \begin{tabular}{l}
\multirow{Z}{0}{} \\
$\infty$ \\
0 \\
0
\end{tabular} & $\begin{array}{l}\text { DO1_4 Za naše poduzeće, } \\
\text { bilo je strateški nužno } \\
\text { započeti s uporabom BIS-a. }\end{array}$ & \\
\hline $\begin{array}{l}\text { TD1_6 Uporaba BIS-a } \\
\text { omogućuje veću kontrolu } \\
\text { nad poslovanjem }\end{array}$ & $\frac{\infty}{2}$ & $\begin{array}{l}\text { OD1_6 Postoji jedna ili više } \\
\text { osoba na razini menadžmenta } \\
\text { koja konstantno ističe predno- } \\
\text { sti BIS-a. }\end{array}$ & $\frac{0}{2}$ & & $\begin{array}{l}7 \\
\infty \\
0\end{array}$ \\
\hline TD2 & Vr. & OD2 & Vr. & $\mathrm{DO} 2$ & Vr. \\
\hline $\begin{array}{l}\text { TD2_1 Proces upozna- } \\
\text { vanja s radom BIS-a bio } \\
\text { je složen. }\end{array}$ & ळ) & $\begin{array}{l}\text { OD2_1 Menadžeri i zapos- } \\
\text { lenici znaju kako koristiti IT } \\
\text { za potporu poslovanju. }\end{array}$ & $\begin{array}{l}7 \\
\infty \\
0\end{array}$ & $\begin{array}{l}\text { DO2_1 Reputacija proiz- } \\
\text { vođača i/ili ponuditelja } \\
\text { softvera je bitna prilikom } \\
\text { izbora BIS-a. }\end{array}$ & $\begin{array}{l}+ \\
0 \\
\infty \\
0\end{array}$ \\
\hline $\begin{array}{l}\text { TD2_2 Proces uvođenja } \\
\text { BIS-a bio je složen. }\end{array}$ & $\frac{1}{0}$ & $\begin{array}{l}\text { OD2_2 Menadžeri i zapos- } \\
\text { lenici dobro razumiju kako } \\
\text { koristiti BIS u poslovanju. }\end{array}$ & $\frac{2}{2}$ & $\begin{array}{l}\text { DO2_2 Tehnološke kompe- } \\
\text { tencije proizvođača softvera } \\
\text { su bitne prilikom izbora } \\
\text { BIS-a. }\end{array}$ & $\begin{array}{l}0 \\
\infty \\
\infty \\
0\end{array}$ \\
\hline $\begin{array}{l}\text { TD2_3 Korištenje BIS-a } \\
\text { je složeno i zahtjevno za } \\
\text { korisnike. }\end{array}$ & $\begin{array}{l}n \\
\infty \\
0\end{array}$ & $\begin{array}{l}\text { OD2_3 Posjedujemo dovol- } \\
\text { jno tehničkih, upravljačkih i } \\
\text { ostalih vještina potrebnih za } \\
\text { prihvaćanje BIS-a. }\end{array}$ & $\begin{array}{l}0 \\
+ \\
\infty \\
0\end{array}$ & $\begin{array}{l}\text { DO2_3 Sposobnost proiz- } \\
\text { vođača i/ili ponuditelja } \\
\text { BIS-a da uspješno provede } \\
\text { projekt uvođenja BIS-a nam } \\
\text { je važna prilikom izbora. }\end{array}$ & $\frac{1}{\infty}$ \\
\hline
\end{tabular}




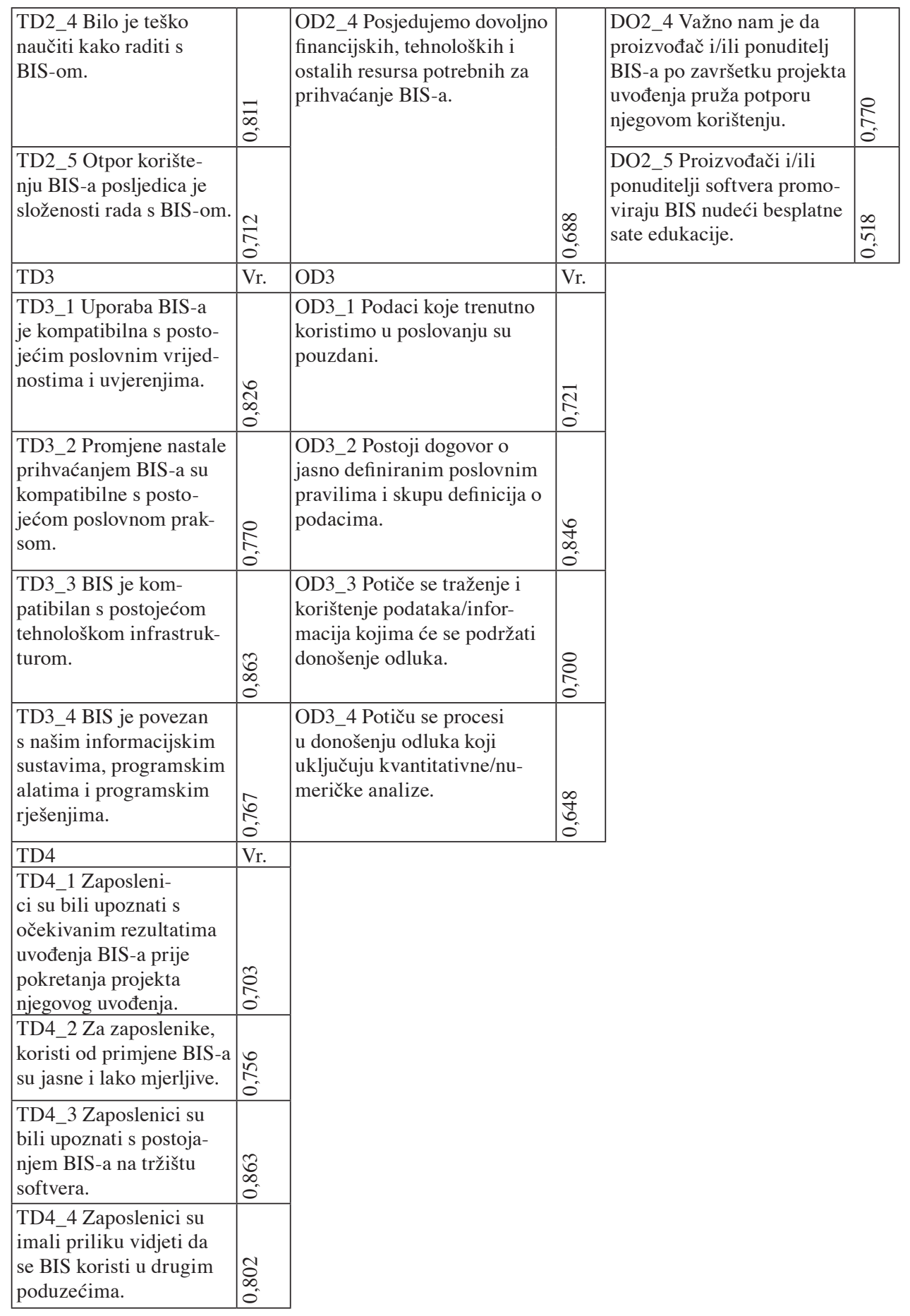

Izvor: autorski rad, 2019. 


\section{ZAKLJUČAK}

Današnje poslovanje većine poduzeća, neovisno o njihovoj veličini, postaje ovisno o pravodobnoj dostupnosti i preciznosti informacija koje proizlaze iz svakodnevnog procesa poslovanja. Sustavi poslovne inteligencije predstavljaju time pogodno rješenje za svako poduzeće koje želi poboljšati svoje postojeće poslovanje te osigurati konkurentsku poziciju na sve turbulentnijem tržištu. Obzirom da mala i srednja poduzeća čine ključni faktor gospodarskog napretka u Republici Hrvatskoj, imajući pri tome u vidu da najvećim dijelom sudjeluju u tercijarnom sektoru čije poslovanje ponajviše ovisi o kvalitetnoj informaciji, provedeno je istraživanje potencijalnih odrednica prihvata na području Republike Hrvatske u uzorku malih i srednjih poduzeća tercijarnoga sektora.

Inicijalni odabir odrednica temeljen je na trima dimenzijama teorijskog okvira za prihvat tehnoloških inovacija pod nazivom Tehnologija - Organizacija - Okruženje. Dimenzije koje obuhvaća spomenuti teorijski okvir su tehnološka, organizacijska i dimenzija okruženja. Podaci su prikupljeni provedbom anketnog upitnika na uzorku od 100 malih i srednjih hrvatskih poduzeća iz tercijarnoga sektora. Prikupljeni podaci su obrađeni i analizirani uz pomoć metode faktorske analize. Rezultati provedene faktorske analize ukazuju na potencijalne odrednice tehnološke dimenzije kao što su: percepcija komparativne prednosti sustava poslovne inteligencije, kompleksnost sustava poslovne inteligencije, kompatibilnost sustava poslovne inteligencije i mogućnosti procjene koristi sustava poslovne inteligencije. Unutar organizacijske dimenzije faktorskom analizom definirane su sljedeće potencijalne odrednice: organizacijska podrška, organizacijska spremnost i kvaliteta upravljanja podacima kao podrška donošenju odluka, dok su se potencijalnim odrednicama unutar dimenzije okruženja pokazale odrednice pritiska konkurencije i kvaliteta proizvođača i/ili ponuditelja softvera sustava poslovne inteligencije.

Daljnje ispitivanje utjecaja svake navedene odrednice dimenzija odabranog teorijskog okvira, kao i sumarnog utjecaja dimenzija na prihvat sustava poslovne inteligencije na uzorku hrvatskih malih i srednjih poduzeća tercijarnoga sektora, planira se provesti u budućim radovima ove istraživačke teme. Time se planira detektirati potencijalan utjecaj odabranih odrednica iz tehnološke i organizacijske perspektive poslovanja hrvatskih malih i srednjih poduzeća tercijarnoga sektora, na uspješnu realizaciju primjene funkcionalnosti sustava poslovne inteligencije. S druge strane, daljnja analiza uspostavljenih odrednica odredila bi utjecaj eksterne perspektive poslovanja promatranih poduzeća na prihvat sustava poslovne inteligencije, što bi pružateljima softvera sustava s područja Republike Hrvatske, pružilo smjernice u kreiranju i realizaciji njihove poslovne strategije usmjerene malim i srednjim poduzećima tercijarnoga sektora kao potencijalnim potrošačima.

Ograničenja ovog istraživanja oslanjaju se na veličinu uzorka kao i na karakteristike uzorka. U skladu s time, preporuke za daljnja istraživanja su provođenje istraživanja na većem uzorku malih i srednjih poduzeća tercijarnoga sektora, kao i provođenje istraživanja na velikim poduzećima i/ili poduzećima ostalih sektora u Republici Hrvatskoj. 


\section{LITERATURA:}

1. Acheampong, O. i Moyaid, S. A. (2016). An integrated model for determining business intelligence systems adoption and post-adoption benefits in banking sector. Journal of Administrative and Business Studies, 2 (2), str. 84-85.

2. Adeyelure, T. S., Kalema, B. M. i Bwalya, K. J. (2016). Development of Mobile Business Intelligence framework for small and medium enterprises in developing countries: Case study of South Africa and Nigeria. U: 2016 4th International Symposium on Computational and Business Intelligence (ISCBI), IEEE, str. 11-14.

3. Aghaei Chadegani, A., Salehi, H., Yunus, M., Farhadi, H., Fooladi, M., Farhadi, M. i Ale Ebrahim, N. (2013). A comparison between two main academic literature collections: Web of Science and Scopus databases. Asian Social Science, 9 (5), str. 18-26.

4. Ahmad, S. i Miskon, S. (2019). The Adoption of Business Intelligence Systems in Textile and Apparel Industry: Case Studies. U: Saeed, F., Mohammed, F., Gazem, N. ur., International Conference of Reliable Information and Communication Technology IRICT 2019: Emerging Trends in Intelligent Computing and Informatics, str. 12-23.

5. Ajzen, I. (1985) From Intentions to Actions: A Theory of Planned Behavior. U: Julius Kuhl, J. Beckmann, J., ur., Action Control, str. 11-39.

6. Apraksin, D., Stylianou, E. i Scherbinin, N. (2018). Business Intelligence and Learning Analytics as Contributors to a Data Driven Education Industry. U: 2018 International Conference on Engineering Technologies and Computer Science (EnT) IEEE, str. 11-13.

7. Arefin, M. S., Hoque, M. R. i Rasul, T. (2020). Organizational learning culture and business intelligence systems of health-care organizations in an emerging economy. Journal of Knowledge Management.

8. Arnott, D., Lizama, F. i Song, Y. (2017) Patterns of business intelligence systems use in organizations. Decision Support Systems, 97, str. 58-68.

9. Aruthari, S. i Hasan, H. M. (2005). A grounded study of ERP adoption and vendor selection in Thailand. U: Campbell, B., Underwood, J. i Bunker, D. ur., Australasian Conference on Information Systems Sydney, Australia: Australasian Chapter of the Association for Information Systems, str. 32-38.

10. Azvine, B., Cui, Z., Nauck, D. D. i Majeed, B. (2006). Real time business intelligence for the adaptive enterprise. U: The 8th IEEE International Conference on E-Commerce Technology and The 3rd IEEE International Conference on Enterprise Computing, E-Commerce, and E-Services (CEC/EEE'06), IEEE, str. 29-29.

11. Baker, J. (2012) The technology-organization-environment framework. U: Dwivedi, Y.K. i sur. (ured.) Information systems theory, New York, NY: Springer, str. 231-245.

12. Becerra-Godinez, J. A., Serralde-Coloapa, J. L., Ulloa-Marquez, M. S., Gordillo-Mejia, A. i Acosta-Gonzaga, E. (2020). Identifying the main factors involved in business intelligence implementation in SMEs. Bulletin of Electrical Engineering and Informatics, 9 (1), str. 304-310. 
13. Bellini, E. (2012). Which Collaboration Strategy for the Networked Enterprise in Wine Industry? Technological and Organizational Challenges, U: Anastasi $i$ sur. (ured.): Methodologies and Technologies for Networked Enterprises: ArtDeco Adaptive Infrastructures for Decentralised Organisations, Springer-Verlag Berlin Heidelberg, str. 17-30.

14. Biroğul, S. i Gültekin, H. B. (2020). Reviewing The Effect of Business Intelligence on Decision Support Process: An Application on The Finance Sector. Bilişim Teknolojileri Dergisi, 13 (2), str. 197-206.

15. Boonsiritomachai, W. (2014). Enablers affecting the adoption of Business Intelligence: a study of Thai small and medium-sized enterprises. Submitted in partial fulfilment of the requirements of the degree of Doctor of Business Administration, Melbourne: Victoria University.

16. CEPOR (2019). Izvješće o malim i srednjim poduzećima u Hrvatskoj - 2019 [online], http://www.cepor.hr/wp-content/uploads/2015/03/SME-REPORT-2019-HR-WEB. pdf.

17. Chaveesuk, S. (2010). The determinants of the adoption and application of business intelligence: an ERP perspective, [Doktorska disertacija], Melbourne: Victoria University.

18. Cheng, L. i Cheng, P. (2011). Integration: Knowledge management and business intelligence. U: 2011 Fourth International Conference on Business Intelligence and Financial Engineering, IEEE, str. 307-310.

19. Chong, A. Y.-L. i Chan, F. T. S. (2012). Structural equation modeling for multi-stage analysis on Radio Frequency Identification (RFID) diffusion in the health care industry. Expert Systems with Applications, 39 (10), str. 8645.

20. Cvitanušić Brečić, M. (2020). Role of Business Intelligence Systems in Croatian Higher Education Quality Assurance, U: 43. međunarodni skup za informacijsku, komunikacijsku i elektroničku tehnologiju, Opatija, Hrvatska.

21. Davis, F. D. (1985). A technology acceptance model for empirically testing new enduser information systems: Theory and Results, [Doktorska disertacija], Massachusetts Institute of Technology.

22. Eidizadeh, R., Salehzadeh, R. i Esfahani, A. C. (2017). Analysing the role of business intelligence, knowledge sharing and organisational innovation on gaining competitive advantage. Journal of Workplace Learning, 29 (4), str. 250-267.

23. Elbashir, M. Z., Collier, P. A. i Davern, M. J. (2008). Measuring the effects of business intelligence systems: The relationship between business process and organizational performance. International Journal of Accounting Information Systems, 9 (3), str. 135-153.

24. Fishbein, M. (1967). Attitude and the prediction of behavior. U: Fishbein, M. (ur.) Readings in attitude theory and measurement. New York, USA: John Wiley, str. 477492.

25. Gangwar, H., Date, H. i Ramaswamy, R. (2015) Understanding determinants of cloud computing adoption using an integrated TAM-TOE model. Journal of Enterprise Information Management, 28 (1), str. 107-130. 
26. Ghobakhloo, M., Arias-Aranda, D. i Benitez-Amado, J. (2011) Adoption of e-commerce applications in SMEs. Industrial Management \& Data Systems, 111 (8), str. 1238-1269.

27. Gonzales, R. i Wareham, J. (2019). Analysing the impact of a business intelligence system and new conceptualizations of system use. Journal of Economics, Finance and Administrative Science. 24 (48), str. 345- 368.

28. Grandon, E. E. i Pearson, J. M. (2004). Electronic commerce adoption: an empirical study of small and medium US businesses. Information \& management, 42 (1), str. 197-216.

29. Gu, V. C., Cao, Q. i Duan, W. (2012). Unified Modeling Language (UML) IT adoption - a holistic model of organizational capabilities perspective. Decision Support Systems, 54 (1), str. 257-269

30. Hair, J. F., Black B., Babin, B., Anderson, R. E., Tatham, R. L. (2005). Multivariate Data Analysis, 6th ed. New Jersey: Prentice Hall.

31. Hill, B. D. (2011). Sequential Kaiser-Meyer-Olkin Procedure as an alternative for determining the number of factors in common-factor analysis: a Monte Carlo Simulation, Doktorska disertacija, Oklahoma State University.

32. Hrvatski zavod za zapošljavanje (2012). Područni ured Čakovec u Brnu sudjelovao na seminaru: Razvojne mogućnosti tercijarnog sektora kao najdinamičnijeg dijela ekonomije [online], Dostupno na: http://www.hzz.hr/print.aspx?id=22697.

33. Hwang, H. G., Ku, C. Y., Yen, D. V. i Cheng, C. C. (2004). Critical factors influencing the adoption of data warehouse technology: a study of the banking industry in Taiwan. Decision Support Systems, 37 (1), str. 1-21.

34. Iacovou, C. L., Benbasat, I. i Dexter, A. S. (1995). Electronic data interchange and small organizations: Adoption and impact of technology. MIS Quarterly, 19 (4), str. 465-485.

35. Ifinedo, P. (2011). An empirical analysis of factors influencing Internet/e-business technologies adoption by SMEs in Canada. International Journal of Information Technology \& Decision Making, 10 (04), str. 731-766.

36. Jalil, N. A., Prapinit, P., Melan, M. i Mustaffa, A. B. (2019). Adoption of Business Intelligence-Technological, Individual and Supply Chain Efficiency, U: 2019 International Conference on Machine Learning, Big Data and Business Intelligence (ML$B D B I$ ), IEEE, str. 67-73.

37. Karsak, E. E. i Ozogul, C. O. (2009). An integrated decision making approach for ERP system selection. Expert Systems with Applications, 36 (1), str. 660-667.

38. Kaur, P. i Mahanti, N. C. (2008). A fuzzy ANP-based approach for selecting ERP vendors. International Journal of Soft Computing, 3 (1), str. 24-32.

39. Khan, H. i Faisal, M. N. (2015). A Grey-based approach for ERP vendor selection in small and medium enterprises in Qatar. International Journal of Business Information Systems, 19 (4), str. 465-487.

40. Kiss, I. (2012). Faktorska analiza stavova odrasle populacije prema cjeloživotnom obrazovanju. Napredak: Časopis za interdisciplinarna istraživanja u odgoju i obrazovanju, 153(1), str. 77-94. 
41. Kulkarni, U., Robles-Flores, J. A. i Popovič, A. (2017). Business Intelligence Capability: The Effect of Top Management and the Mediating Roles of User Participation and Analytical Decision-Making Orientation. Journal of the Association for Information Systems, 18 (7), str. 516-541.

42. Kumar, V., Maheshwari, B. i Kumar, U. (2002). Enterprise resource planning systems adoption process: a survey of Canadian organizations. International Journal of Production Research, 40 (3), str. 509-523.

43. Liao, Y., Hong, P. i Rao, S. S. (2010). Supply management, supply flexibility and performance outcomes: an empirical investigation of manufacturing firms. Journal of Supply Chain Management, 46 (3), str. 6-22.

44. Meyer, M. (2000). Innovation roles: From souls of fire to devil's advocates. Journal of Business Communication, 37(4), str. 328-347.

45. Moore, G. C. i Benbasat, I. (1991). Development of an instrument to measure the perceptions of adopting an information technology innovation. Information systems research, 2 (3), str. 192-222.

46. Nacionalno vijeće za znanost, visoko obrazovanje i tehnološki razvoj (2017). Pravilnik o uvjetima za izbor u znanstvena zvanja. NN 28/2017, 652 [online], Dostupno na: https://narodne-novine.nn.hr/clanci/sluzbeni/2017_03_28_652.html.

47. Olexova, C. (2014). Business intelligence adoption: a case study in the retail chain. WSEAS transactions on business and economics, 11 (1), str. 95-106.

48. Oliveira, T., Thomas, M. i Espadanal, M. (2014). Assessing the determinants of cloud computing adoption: An analysis of the manufacturing and services sectors. Information \& Management, 51 (5), str. 497-510.

49. Park, Y. i Chen, J. V. (2007). Acceptance and adoption of the innovative use of smartphone. Industrial Management \& Data Systems, 107(9), str. 1349-1365.

50. Pathan, Z. H., Jianqiu, Z., Akram, U., Latif, Z., Khan, M. K. i Tunio, M. Z. (2017) Essential factors in cloud-computing adoption by SMEs. Human Systems Management, 36 (4), str. 261-275.

51. Pirttimaki, V. H. (2007). Conceptual analysis of business intelligence. South African journal of information management, 9(2), str. 1-1.

52. Porfírio, J. A. i dos Santos, J. C. (2011). Business Intelligence as a service-strategic tool for competitiveness. U: International Conference on ENTERprise Information Systems, Berlin, Heidelberg: Springe, str. 106-117.

53. Premkumar, G. i Roberts, M. (1999). Adoption of new information technologies in rural small businesses. Omega-International Journal of Management Science, 27(4), str. 467484.

54. Puklavec, B., Oliveira, T. i Popovič, A. (2018). Understanding the determinants of business intelligence system adoption stages. Industrial Management \& Data Systems, 118 (1), str. 1-35.

55. Radoš, T., Bezjak, D., Rajaković, M., Mršić, A., Basarac, G., Grubešić, B., Ivanović, I., Jukić, V., Ferara Blaškić, K., Lakoš, I. i Kramarić, V. (2014). Strategija poticanja inovacija Republike Hrvatske, Zagreb: Narodne novine, [online], Dostupno na: http:// narodnenovine.nn.hr/clanci/sluzbeni/dodatni/434155.pdf. 
56. Ramamurthy, K. R., Sen, A. i Sinha, A. P. (2008). An empirical investigation of the key determinants of data warehouse adoption. Decision support systems, 44 (4), str. 817-841.

57. Rogers, M. E. (1983) Diffusion of innovations 3th edition. New York: Free Press.

58. Rostek, K. (2013) Dedicated business intelligence system for SMEs consortium. African Journal of Business Management, 7 (13), str. 999-1014.

59. Salleh, K. A. i Janczewski, L. (2016) Adoption of Big Data Solutions: A study on its security determinants using Sec-TOE Framework. U: International Conference on Information Resources Management (CONF-IRM), Association for Information Systems AIS Electronic Library (AISeL), 66, str. 1-12.

60. Sang, G., Xu, L. i de Vrieze, P. T. (2016). Implementing a Business Intelligence System for small and medium-sized enterprises, U: Conference: SQM 2016: 24th International Software Quality Management Conference, Velika Britanija: Bournemouth.

61. Sechi, G. M., Migliori, M., Dassi, G., Pagliosa, A., Bonora, R., Oradini-Alacreu, A., Odone, A., Signorelli, C. i Zoli, A. (2020). Management of Emergency Services in Lombardy during COVID-19 epidemic using Business Intelligence. European Journal of Public Health, 30 (Supplement_5), str. 65-431.

62. Soloukdar, A. i Parpanchi, S. (2015). Comparing fuzzy AHP and fuzzy TOPSIS for evaluation of business intelligence vendors. Decision science letters, 4 (2), str. 137164.

63. Tornatzky, L. G. i Fleischer, M. (1990) The Processes of Technological Innovation. Massachusetts: Lexington Books.

64. Troshani, I., Rampersad, G. i Plewa, C. (2011) Adopting innovation management software in university innovation commercialization. Journal of Computer Information Systems, 52 (2), str. 83-92.

65. Venkatesh V., Morris M. G., Davis G. B. i Davis F. D. (2003). User acceptance of information technology: Toward a unified view. MIS quarterly, 27 (3), str. 425-478.

66. Wang, Y. M., Wang, Y. S. i Yang, Y. F. (2010). Understanding the determinants of RFID adoption in the manufacturing industry. Technological forecasting and social change, 77 (5), str. 803-815.

67. Wixom, B. H. i Watson, H. J. (2001). An empirical investigation of the factors affecting data warehousing success. MIS quarterly, 25 (1), str. 17-41.

68. Yeoh, W. i Koronios, A. (2010) Critical success factors for business intelligence systems. Journal of computer information systems, 50 (3), str. 23-32.

69. Zakon o računovodstvu (2019) [online], Dostupno na: https://www.zakon.hr/z/118/Zakon-o-ra\%C4\%8Dunovodstvu.

70. Zhu, K. i Kraemer, K. L. (2005). Post-Adoption Variations in Usage and Value of Business by Organizations: Cross-Country Evidence from the Retail Industry. Information Systems Research, 16 (1), str. 61-84. 